\title{
Un Cacique Gaditano en la Segunda República: Ramón de Carranza
}

\author{
JOAQUIN M" PIÑEIRO BLANCA.
}

En líneas generales, un cacique en la ciudad de Cádiz durante los últimos años la Restauración podía responder al siguiente cuadro de características: un individuo miembro de una de las conocidas familias de la capital, que desarrollaba negocios particulares casi siempre relacionados con el mar o con explotaciones en la comarca del Jerez, y que había ostentado diversos cargos políticos a nivel local o provincial en los partidos de turno. De todos estos rasgos participaba Ramón de Carranza y Fernández de la Reguera, personaje que nos ocupa en el presente estudio.

A pesar de no haber nacido en el seno de una notable familia gaditana -su origen era gallego-, consiguió ingresar en este destacado grupo de la ciudad a través de su matrimonio, en 1890, con Josefa Gómez de Aramburu ${ }^{1}$. Gracias al respaldo económico y político de esta importante: familia, a la rentabilidad obtenida de su carrera militar en la guerra de $\mathrm{Cuba}^{2}$ y a la adquisición del título de Marqués de Villapesadilla ${ }^{3}$, se encontró en situación de poder desarrollar un gran capital en negocios de almadrabas y en buques de pesca ${ }^{4}$ y de iniciar una prometedora carrera políticr en el Partido Conservador que lo llevó a ostentar los cargos de diputado por el distrito de Algeciras (1903-1905), senador por la provincia de Cádiz (1907-1918) y diputado por el distrito de El Puerto

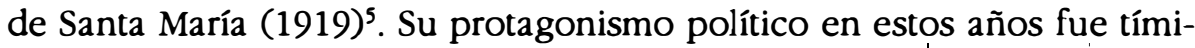
do, pero le permitió ir consolidando una privilegiada posición entre los caciques más influyentes en la provincia de Cádiz.

(1) Cfr. Diario de Cádiz, 5 de marzo de 1890; Según datos obtenidos en entrevista con las farnilias Carranza y Picardo (26 de enero de 1990).

(2) Cfr. Estado General de la Armada para 1901, pp. 48-50.

(3) Cfr. DE ATIENZA, J.: Nobilianio Español. Madrid, 1954, p. 999.

(4) Cfr. Guías Anuario de Cádiz y su provincia para 1923, 1927 y 1930, Cfr. Diario de Cádiz, 17 de diciembre de 1928; Según datos obtenidos en entrevista con las familias Carranza y Picardo (23 de marzo de 1990).

(5) Cfr. Diarios de Sesiones de las Contes, 1903-1919.

DOI: http://dx.doi.org/10.25267/Trocadero.1993.i5.28 
Tras presidir la Junta de Obras del Puerto y la Sociedad de Turismo en la primera mitad de la década de los veinte, es nombrado por Miguel Primo de Rivera -a instancias de José María Pemán- alcalde de Cádiz en 1927, cargo que ocupa hasta la proclamación de la República en abril de 1931. En este período, Carranza alcanzó el punto más alto de su poder político en la ciudad, lo que finalmente lo colocaría a la cabeza de los grupos monárquicos tradicionales gaditanos.

El 21 de enero de 1931 se convocan elecciones municipales por el gobierno del Almirante Aznar con el fin de renovar los ayuntamientos españoles. Estas se celebrarían el 12 de abril con arreglo al censo electoral de 1930 y a la ley de 1907 . En la candidatura presentada por los viejos monárquicos, Ramón de Carranza dejaba su espacio -aunque sólo fuese momentáneamente- a su hijo José León animado por una decisión de una, supuestamente, retirada paulatina de la política activa. Tras los problemas surgidos entre José.María Pemán, por un lado, y el Conde de los Andes y José León de Carranza, por otro, debido a la política de pactos con todas las fuerzas monárquicas provinciales ${ }^{6}$, quedaron estos dos últimos como los máximos dirigentes del conservadurismo monárquico gaditano. Finalmente se presenta una lista única bajo el nombre de Frente Monárquico ${ }^{7}$.

En Cádiz, contrariamente a lo sucedido en el resto de España, los partidos dinásticos disfrutaron de una situación de privilegio, dado que Berenguer se apoyó en esta capital en los mismos elementos que sirvieron a Primo de Rivera: Ramón y José León de Carranza, el Conde de los Andes y José María Pemán. Todos ellos, durante la Dictadura, fueron ganando terreno en detrimento de otros caciques, lo que les permitió el poder controlar toda la política "oficial. del momento.

Otra circunstancia que convierte a los monárquicos gaditanos en una fortaleza con respecto a los del resto de España, fue la de que, en Cádiz, los antiguos partidos dinásticos habían seguido existiendo durante la Dictadura de Primo de Rivera sin ningún tipo de problemas, al amparo protector de la Unión Patriótica. Así, durante el gobierno de Berenguer,

(6) La disputa acerca de la estrategia más adecuada para estas elecciones provoca la dimisión de José María Pemán de la Jefatura Provincial de la Unión Monárquica Nacional (partido heredero de la Unión Patriótica, es decir, de los antiguos seguidores de Miguel Primo de Rivera). Pemán defendía una política de pactos menos amplia que la diseñada por sus compañeros. Desaparecido dọn José María de la escena política, el Conde de los Andes y José León de Carranza dirigirán los grupos monárquicos tradicionales con un reparto de influencias: el primero en la provincia y el segundo en la capital. Cfr. TUSELL, J.: La crisis del caciquismo andaluz, 1923-1931. Madrid, 1977. pp. 358 y ss.; CARO CANCELA, D.: La Segunda Repüblica en Cádiz. Elecciones y partidos poláticos. Cádiz, 1987. pp. 58-60

(7) Cfr. Diario de Cádiz, 8 de marzo de 1931.

(8) Cfr. CARO CANCELA, D.: La Segunda República... Op. Cit. p. 60. 
las luchas entre emonárquicos del viejo régimen* y "monárquicos de la Dictadura* no tuvieron efecto porque en esta provincia eran los mismos? Ante tales circunstancias, no es de extrañar que el caciquismo electoral de los años finales de la Restauración se activase de nuevo y que fuesen, precisamente, los monárquicos los que obtuviesen la victoria en Cádiz capital y en varios municipios importantes de la provincia ${ }^{10}$. A esto ayudó que el republicanismo gaditano estuviese mal organizado y que una parte importante del proletariado se abstuviese por influencia de las ideas anarquistas ${ }^{11}$. Pero la proclamación de la Segunda República el 14 de abril de 1931 dio al traste con estas posiciones. La sorpresa producida por el cambio de régimen político motivó que los Carranza y sus seguidores, tras la disolución de sus partidos, no participasen en las nuevas elecciones del 28 de junio ${ }^{12}$.

Las elecciones legislativas de 1933 marcan el regreso de Ramón de Carranza a la política activa, esta vez sin delegar en su hijo José León, viéndose en este gesto un cambio de actitud con respecto a 1931: „España se bunde y yo no voy a permanecer impasible ${ }^{13}$, dirá. Carranza es el primero en incorporarse al nuevo partido católico-tradicionalista-integrista en Cádiz, e incluso le da su nombre: Acción Ciudadana ${ }^{14}$.

De estas fechas es precisamente un importante discurso pronunciado por Ramón de Carranza en la sede de Acción Ciudadana en Cádiz, el domingo 30 de abril de 1933. En él quedó plasmado gran parte del pensamiento político del personaje que nos ocupa, y, por extensión, del de toda la derecha monárquica gaditana del momento ${ }^{15}$. Como veremos, básicamente iba encaminado a recuperar los principales elementos del programa

(9) Cfr. TUSELL, J.: La crisis del caciquismo ... Op. Cit. pp. 274-275.

(10) Cfr. CARO CANCELA, D.: La Segunda República en ... Op. Cit. pp. 76-77; Cfr. TUSELL, J.: La crisis del cactquismo ... Op. Cit. p. 432.

(11) Cfr. CARO CANCELA, D.: La Segunda República en ... Op. Cü. p. 405; Cfr. TUSELL, J.: La crisis del caciquismo ... Op. Cir. p. 419.

(12) Cfr. CARO CANCELA, D.: La Segunda Repüblica en ... Op. Cut. p. 108.

(13) La Información, 23 de enero de 1933; El Noticiero Gaditano, 8 de febrero de 1933; Según datos obtenidos en entrevista con las familias Carranza y Picardo (26 de enero de 1990).

(14) Cfr. ARTOLA, M.: Partidos y programas políticos, 1808-1936. I Los partidos políticos. Madrid, 1977. p. 614; CARO CANCELA ,D.: La Segunda República en ... Op. Cit. pp. 128 129; Vid. GALINDO HERRERO, S.: Los partidos monárquicos bajo la Segunda Repüblica. Madrid, 1956.

(15) Este discurso, de exaltado patriotismo, fue publicado en forma de folleto para que cumpliese con sus fines propagandísticos. La validez de lo expuesto en el mismo se quiso fortalecer indicando que el numeroso público era formado por -representaciones de todas las clases sociales, y sobre todas se destacaba la obrera, por su nümero y por su calidad, ansiosas porque el ídolo del pueblo gaditano iba a decirles la verdad, sin ambajes ni rodeos. CARRANZA, R. de: Discurso pronunciado por el Excmo. Sr. Don ...., el domingo treinta de abril en el domicilio de Acción Ciudadana. Cádiz, 1933. pp. 4-5. 
político desarrollado por Carranza desde la alcaldía de Cádiz durante la Dictadura de Primo de Rivera. Era, en palabras de don Ramón, el rúnico camino factible para salvar a España de los desastres bacia los que la encaminaba la República ${ }^{16}$.

Carranza desarrolla su discurso al amparo de un esquema determinado, aunque en su lectura no se manifieste de la forma ordenada en que lo vamos a presentar aquí, tal vez porque el modelo seguido por don Ramón responda más a una actitud instintiva que a algo sistemáticamente meditado (ésta era, en definitiva, una de las notas que caracterizaron la actuación política de Ramón de Carranza a lo largo de toda su carrera). Este modo de exponer sus ideas es básicamente el mismo desde los inicios de su actividad política, aunque ahora lo hace de forma mucho menos sutil y eficiente que entonces, quizás debido a la radicalización de su postura derivada de la coyuntura hostil que para él suponía el régimen republicano, a lo precario de su salud y a lo avanzado de su edad en este momento.

Por regla general, todo orador, en el desarrollo de su discurso, desgrana una serie de informaciones de variada índole acerca de su persona intencionada o involuntariamente- a fin de ir creando en el oyente una determinada imagen que otorgará el matiz y la credibilidad deseadas en los mensajes lanzados. Ramón de Carranza, en este aspecto, se mostró transparente. Aislando todos los destellos personales incluidos en su oratoria, podemos deducir fácilmente cuál era el retrato que de si mismo gustaba pintar.

Ante todo, se mostró con las características propias de un talante sincero y claro en todo lo que hacía o decía, porque, según explicaba, alas verdades siempre amargan ${ }^{17}$. En numerosas ocasiones se manifestaría en este sentido con expresiones semejantes a la siguiente: pudiendo vosotros estar seguros de esto, pues, como vulgarmente se dice, voy a bablaros más con el corazón que con la cabeza." La veracidad y la sinceridad son dos de las condiciones indispensables que todo pensador debe tener en cuenta para lograr captar a unos posibles seguidores, de ahí que Carranza intentara desterrar de su persona cualquier sospecha de mentira y/o confusión en los planteamientos.

En relación con esto, don Ramón también intentaría presentarse como un hombre de palabra, que cumplía lo que prometía. En este sentido, su actuación al frente del Ayuntamiento gaditano sería utilizada como una

(16) TUSELL, J.: La crisis del caciquismo ... Op. Cit. p. 375. Tusell establece como uno de los tres argumentos fundamentales barajados en la propaganda electoral monárquica en abril de 1931, el de presentar a dicha candidatura como símbolo y materialización del orden y la tranquilidad frente a la perturbación de lo desconocido.

(17) CARRANZA, R. de: Discurso pronunciado por... Op. Cit. p. 24.

(18) Ibidem. p. 3. 
prueba importante. Con ello intentaba ofrecer la seguridad de que todo lo que decía sería puesto en práctica, y, en su opinión, nada era mejor que recordar su ejemplar comportamiento en el pasado. Otro argumento más dado por don Ramón para que se depositase confianza en él.

Por otro lado, también estuvo presente la voluntad de desprender una imagen de generosidad y humildad, ausente de altanería e inspiradora de una cierta ternura, pero no por ello débil o incapaz de llevar a cabo lo que defendía. Esto lo llevó a reconocer que era aun malísimo orador.....y] un osado pretencioso [...por] hablar donde ya lo ba hecho el vate José $M^{a}$ Pemán ${ }^{29}$. Las costantes menciones a su debilidad física otorgaban mayor valor a lo que hacía. Según sus propias palabras, él hubiera podido retirarse a descansar, pero, heroicamente, ha preferido ofrecer los últimos años de su vida a seguir luchando por el bien común. Esta incapacidad física lo podía transformar en un ser más inofensivo y digno de mayores simpatías, pero esto no quería significar, según don Ramón, que fuese un pusilánime incapaz de luchar por sus ideas, y por tanto, un ser inútil para servir al pueblo.

Esta táctica de Carranza podría haber sido más eficaz si en otros puntos del discurso no aparecieran llamativas alabanzas a su labor política anterior, no descalificase duramente a todos aquellos que osaban criticar su actuación (esto a pesar de que, tras fuertes palabras contra políticos republicanos por parte del público, Carranza indicó que no consentía frases ofensivas para nadie y que pudiesen degenerar en algo desagradable) y si su lenguaje no fuese en todo momento imperativo y categórico. Características alejadas de la imagen de apacible anciano de salud quebrantada que intentaba mostrar.

La conducción de su oratoria como si ésta fuese una conversación informal entre él y su auditorio (el lenguaje utilizado se presentaba en primera persona) llenaron todas sus intervenciones en público desde los inicios de su carrera política. Con este matiz claramente populista acentuaba la sensación de cercanía y aumentaba considerablemente las posibilidades de conexión con el oyente: ¿¿Podré contar con vosotros, con todos como un sólo hombre y un sólo corazón que lata al par que el mio?, respondedme ¿si o no? $?^{20}$. Probablemente esta capacidad explique en parte su eficacia como orador, según se desprende de testimonios acerca de él de sus contemporáneos.

Todos estos recursos encaminados a orientar los sentimientos del público en favor del que desarrolla el discurso entrarían dentro de lo relativamente normal. La peculiaridad radicaba en el hecho de que Ra-

(19) Ibidem. pp. 8 y 25.

(20) Ibidem. pp. 24-25. 
món de Carranza elaboró un retrato completo, impersonal, del alcalde ideal que Cádiz necesitaba para resolver sus problemas, retrato que venía a coincidir -de forma solapada- con el que don Ramón intentaba pintar de si mismo: un individuo honesto consigo mismo y con los demás, lejos de las corrupciones imperantes en los políticos republicanos, un hombre que cumplía lo que prometía, de probados y sabidos conocimientos sobre la administración de Cádiz, cuyo único interés fuese el amor a la ciudad que gobierna, y que esto lo hubiese demostrado ya en el pasado, para mayor seguridad. El avispado oyente, si había sido conducido finalmente por los caminos que el orador había elegido, no podía por menos que concluir que Ramón de Carranza era el político más apropiado para solucionar los problemas gaditanos ${ }^{21}$.

Paralelamente a este intento de valoración de su persona, cimiento importante para el éxito de sus pretensiones políticas, desarrolló lo que fue la gran columna de sustento de los ideales que pretendía implantar.

Como indicábamos en páginas precedentes, en las elecciones municipales de 1931, Carranza había decidido iniciar una retirada paulatina de la política activa en favor de su hijo José Léon, pero el curso de los acontecimientos lo empujaron, al parecer, a volver nuevamente a ella. La pregunta del porqué de su regreso estaba en el aire, y Carranza la responde a su manera, intentando, de camino, sacar el mayor provecho posible de ello al transformar su respuesta en una colección más de argumentos conducentes a un fin: convencer a los gaditanos de que la ciudad necesitaba a Ramón de Carranza para alcanzar su desarrollo. Las razones dadas a su vuelta a la política activa eran las dos caras de una misma moneda: defenderse de las que él consideraba injustas acusaciones y críticas a su administración anterior por parte del gobierno de la República, y culminar el programa político iniciado en 1927. En definitiva, la revalidación del régimen dictatorial y la invalidación del republicano.

Las acusaciones que motivaron el regreso de Carranza al primer plano de la vida política gaditana tienen un nombre: el «Expediente Barahona*. A petición de un teniente de alcalde del primer Ayuntamiento gaditano en la Segunda República, tras ser aprobada la propuesta por unanimidad, se acuerda solicitar del Ministerio de la Gobernación una visita con el fin de inspeccionar la gestión de los ayuntamientos de la Dictadura. Esta petición fue aceptada por Madrid, que envía a un funcionario administrativo, Manuel de Barahona, a cumplimentarla. Los resultados de su investigación fueron recogidos en el aludido expediente ${ }^{22}$. En él se ponía en entredicho la regularidad de la gestión de Carranza al frente de la alcaldía gaditana.

(21) Cfr. La Información, 2 de mayo de 1933.

(22) Cfr. Avance, 28 de enero; 4, 11, 18 y 25 de febrero; y 11 de abril de 1933. 
Don Ramón planteó su defensa basándose exclusivamente en el ataque a sus enemigos con los mismos argumentos con los que él había sido atacado, mostrando con frecuencia una actitud prepotente ${ }^{23}$. Sin embargo, no intentó refutar las críticas que se le hicieron de forma concreta, lo que, evidentemente, no mejoraría su posición frente a sus enemigos políticos.

A las acusaciones de corrupción respondió que el ateniente de alcalde que se habia sentido puritano en aquel Pleno, olvidó después en su actuación el puritanismo demostrado en dicha sesión, y decidió utilizar a los obreros del Ayuntamiento en reparaciones de su casa de Puertas de Tierra, con materiales también del municipio ${ }^{24}$. Una denuncia del arquitecto municipal, Sr. Hidalgo (antiguo colaborador de Carranza), sacó a la luz pública este asunto. La solución dada al problema tampoco le resultó satisfactoria ya que el asunto, según su parecer, no debió tratarse en la Sala Capitular, sino en el juzgado de Instrucción, que era quien definía los delitos.

Frente a la corrupción que denuncia en sus acusadores, Carranza se presenta como alguien que está por encima del bien y del mal, una persona a la que no se podía ofender porque, según sus palabras, estoyy estamos los que entonces constituíamos el Cabildo a tal altura, que esos conceptos no nos alcanzan (...J. Hasta abora van a la cârcel los que cometen delitos y no los que por un error de tramitación faltan a lo estatuido. ${ }^{25}$.

A las denuncias que se refirieron al estado de bancarrota al que había llevado a la hacienda municipal por su desmedida campaña de obras públicas, respondió que el Ayuntamiento republicano vivía -de un presupuesto de 13.200 .000 pesetas que, gracias a nuestras administraciones, es lo que dispone en la actualidad el Ayuntamiento para sus despilfarros y derrocbes, viviendo en el más anárquico desorden, diciendo tienen superâvit de miles de pesetas, cuando la verdad es un déficit de doble número de ellas, representando un millón de error, mientras la mitad de la clase obrera padece de innanición ${ }^{26}$.

El desorden administrativo causado, a su juicio, por la gestión de sus acusadores contrastaba, según Carranza, con las «buellas tan visibles y tan

(23) Cuando Carranza fue acusado de llevar a la ruina económica al Ayuntamiento gaditano con su ambiciosa política de obras públicas y de municipalizaciones de servicios afirmó que respondia con su fortuna personal de la gestión realizada, Cfr. CARRANZA, R. de: Discurso pronunciado por ... Op. Cur. p. 6.

(24) Ibidem pp. 4-5.

(25) La.Información, 2 de mayo de 1933. En 1934, Ramón de Carranza consigue la suspensión del Expediente Barahona. con el llamado .Expediente Casas. En él se piden responsabilidades semejantes a los Ayuntamientos de la República.; Cfr. GUILLOTO Y GONZALEZ, F.: Cinco años de la bistoria de Cádiz, 1936-1940. Cádiz, 1988.

(26) CARRANZA, R. de: Discurso pronunciado por ... Op. Cit. p. 7. 
claras de mi paso por el Municipio l..., construí un patrimonio a la ciudad como no lo tiene ninguna de Españar.

Este asunto fue culminado por Carranza ofreciendo una versión de las "ocultas razones" por las que su administración, según su opinión, habría sido tan injustamente denostada: al ser acusados él y sus compañeros de gestión, y condenados, según voluntad expresada por el Ayuntamiento republicano, a ingresar en la cárcel y a perder todos los derechos como ciudadanos", lo que se pretendió fue que, en el caso de ser elegidos como concejales, no pudiesen ocupar sus cargos en tanto durase la tramitación del expediente. Esta se encontraría paralizada el tiempo que fuese preciso para que todavía no estuviese resuelta en el momento de la toma de posesión. Afirmaría lo siguiente: "nunca pude pensar que ningún bijo de Cádiz pretendiera recompensar mi actuación como alcalde, en la que perdi mi tiempo, gran parte de mi fortuna desatendida, y por completo mi salud, metiéndome en la cárcel l...J Lo que temen es sufrir una derrota como en abril de 1933, en la que se vió claramente que republicanos en Cádiz no existian entonces más que en un pequeño número $^{28}$. Es decir, según Carranza, no sólo eran infundadas las acusaciones que se le hicieron, sino que escondian la pretensión de impedir a Carranza consumar una previsible victoria electoral.

Así pues, restablecer su prestigio personal fue uno de los motivos, como decíamos, del regreso de Carranza a la política activa. Y el continuar la labor por él iniciada en la Dictadura -objetivo que el Ayuntamiento republicano se mostraba incapaz de desarrollar en opinión de don Ramón-, fue la otra ${ }^{29}$. Según don Ramón, "cuando gobernaban en el país los que nada entendian de encbufismos y menos de favoritismos, Cádiz logró poseer un importante patrimonio municipal. La ciudad era dueña de un cine, una plaza de toros, un nuevo mercado, un hotel, un matadero, un campo de deportes, la administración de sus servicios de agua y luz, unos preciosos jardines, nuevas escuelas...; “jy serä tan ingrato el pueblo de Cádiz que babrá de preferir en ese día a esos bombres, cuyos nomires en absoluto nada representan en la ciudad, ni por sus conocimientos ni competencia [...], y que pretenden llegar a ser concejales para ser algo, pues nada son?,30.

(27) Ibidem. p. 7.

(28) Ibidem p. 6.

(29) Desde las elecciones de abril de 1931, los monárquicos incluían en su programa, invariablemente, el continuar la labor de don Ramón de Carranza, consolidando su labor municipal y profundizando, a través de ella, en la defensa de la religión, la monarquía y el orden público; Cfr. RAMOS SANTANA, A.: -Apuntes para una crónica del primer tercio del siglo XX. En: I Jornadas de Historia de Cádiz. Cádiz, 1982. p. 130.

(30) CARRANZA, R. de: Discurso pronunciado por... Op. Cit. p. 15. 
Carranza basó su discurso en ideas tales como que su actuación en el pasado probaba su eficacia, que su prestigio personal despejaba dudas acerca de su posible utilización de cargos públicos para encumbrarse (justo lo que podría pensarse de sus «desconocidos y poco importantes" rivales ${ }^{31}$ ), y que en Cádiz se le debía agradecimiento por el bien que a la ciudad reportó su labor. Con estos argumentos intentaba conducir a sus oyentes a la conclusión de que la demostrada eficacia de su programa político no podía ser desaprovechada optando por unas posiciones de las que nada se sabía (y de las que, presumiblemente, y sólo por el hecho de que estaban destruyendo una labor política tan brillante como la suya por puro revanchismo, nada bueno podía esperarse). Se trataba de inculcar la ya mencionada idea de los grupos monárquicos gaditanos que anteponía la tranquilidad de lo conocido frente a la perturbación de lo desconocido, no sólo en las ideas y hechos sino en las personas ${ }^{32}$. Esto lo empujaba a decir sus enemigos políticos temían que el pueblo de Cádiz, si se conduce como debe, y el que no es agradecido no es bien nacido, llevará al Ayuntamiento a personas cuya labor y modo de ser conozca, a aquellos cuyas buellas dejaron muestras tan claras de su paso por el Municipio,33.

A fin de fortalecer la idea de la conveniencia de reanudar su programa administrativo, Carranza se dedicó a explicar lo que, según su parecer, estaba por hacer y lo que supondría su culminación para la ciudad. El punto al que otorgó mayor importancia fue el proyecto de establecimiento en Cádiz de una zona franca: Ramón de Carranza encargó durante la Dictadura al ingeniero municipal Sr. Torroja un estudio completo para instalar una zona franca en los terrenos comprendidos entre Puntales y Punta Cantera, en San Fernando. La importancia de dicho asunto se argumentaría siempre de la misma forma: Cádiz, dado que carece de recursos agrícolas y mineros y no tiene más industria que la de construcción naval con el factor de inestabilidad que ésta siempre tuvo- necesitaba la protección del Estado para conseguir su bienestar económico. Dicha protección se podría materializar del modo más conveniente con la concesión de una zona franca que reactivase la maltrecha economía gaditana.

La concesión se obtuvo, por Real Decreto, en mayo de $1929^{34}$, en palabras de Carranza, "gracias al interés y a la generosidad del Dictador y el Monarca.3. Pero la a probación del presupuesto del proyecto estuvo en tramitación más de un año, y, al fin conseguido, el cambio de régimen -según explicaba don Ramón- lo dejó en suspenso sin que nadie, hasta

(31) ibidem, p. 15.

(32) Cfr. TUSELL, J.: La crisis del caciquismo... Op. Cit. p. 375.

(33) CARRANZA, R. de: Discurso pronunciado por ... op. Cit. p. 7.

(34) Cfr. Diario de Cádiz, 17 de mayo de 1929.

(35) Nota sobre la zona franca en la Babia de Cádiz. Cádiz, 1930. 
entonces, se hubiese preocupado de reclamar del Gobierno el cumplimiento tal concesión.

Además, el derribo de los glacis y cuarteles de Puertas de Tierra se habría abandonado en su momento en espera de que comenzasen las obras en la zona franca, ya que se consideraba innecesario el ensanche de la ciudad mientras no contase con su principal recurso de desarrollo económico y, por tanto, de expansión ${ }^{36}$.

Estos argumentos intentaban cultivar entre el público la creencia de que no existía instrumento mejor para la salvación de Cádiz que una zona franca, a la vez que se dejaba claro que los culpables de que ésta no entrase en funcionamiento eran los miembros del equipo municipal republicano. Nuevamente se incidía en la convicción de que era necesario reanudar el programa político de Carranza.

Otros asuntos pendientes de culminación fueron, según el criterio de Carranza, las obras conducentes a crear una infraestructura hotelera y la urbanización de las playas para la potenciación de los recursos turísticos de la ciudad, la otra vía factible para solucionar los problemas económicos de Cádiz. La reforma del mercado de abastos, el derribo de los glacis y cuarteles de Puertas de Tierra -con el consiguiente ensanche de la ciudad- y la política de ornato y limpieza pública también quedaron sin terminar, en opinión de Carranza, en el afán demostrado por destruir nuestra obra y que ni el recuerdo pueda quedar de ella ${ }^{37}$.

Curioso fue el enfoque dado por Carranza al abandono de su campaña de limpieza y ornato del casco urbano de Cádiz. La población se encontraba en aquel estado de suciedad porque se estaba adestruyendo lo que otros bicieron [...y con ello] no progresan las poblaciones. Antes estaba que agradaba ver la población en tal grado de limpieza y orden, $y$ todo está abora cambiado [...Lo último que le quedaba por ver eran] los chiquillos, como toritos sueltos, jugando al football en las calles, insultando al que les reprende, cual salvajes africanos ${ }^{38}$.

Pintado el cuadro deseado de su personalidad (que viene a coincidir, como indicábamos, con el del alcalde más apropiado para la ciudad), defendido de las acusaciones que sobre su política se venían efectuando en aquellos días y -una vez desacreditado el régimen político republicano- convencido el auditorio de que la única salida factible para solucionar todos los problemas de Cádiz estaba en la reanudación de un programa que el régimen presente dejaba incompleto, estaban sentadas las bases para arropar, de la forma más conveniente, todo el ideario político

(36) Cfr. CARRANZA, R. de: Discurso pronunciado por... Op. Cit. pp. 19-20.

(37) La información, 2 de mayo de 1933.

(38) Ibidem. 
de Ramón de Carranza y, con él, el de los monárquicos tradicionales gaditanos del momento ${ }^{39}$.

Lós seis puntos básicos que pueden resumir el contenido de la campaña ideológica lanzada por Acción Ciudadana en las elecciones legislativas de 1933 (Religión, Patria, Familia, Orden, Trabajo y Propiedad), se encuentran presentes en el discurso empleado por Carranza en la campaña, ya sea explícita o implícitamente ${ }^{40}$ :

- Patria: Enfocando el tema desde el punto de vista de un gobierno municipal, Carranza lanza dos ideas: la Patria chica era ta verdadera $\mathrm{Pa}$ tria, pues es en la que se vive, la que se toca, la que se ve [... El conjunto de amores a las Patrias chicas [...] constituye el de la Patria grande, que es un mito, un ideal l...J que se diviniza porque no es tangible ${ }^{41}$. Indirectamente, con ello, se tocaba uno de los temas que más le obsesionaron en aquel año: el Estatuto de Autonomía Catalán. De él Carranza hizo las críticas más duras y consideró el asunto antipatriótico, separatista y anárquico, además de un gesto de explotación al resto de España por parte de Cataluña, *cual Bélgica a sus posesiones del Congo ${ }^{42}$. Para Carranza, el verdadero amor a la Patria chica debía convertirse, como se desprende del párrafo insertado más arriba, en una pieza más de un conjunto que formaría el de la verdadera Patria, España. El repudia a cualquier sistema de autonomía producía que fuese vista como un gesto de separatismo destructor.

La segunda idea que defiende con respecto a su concepto de Patria es consecuencia de ésta: el objetivo principal de un Ayuntamiento era *hacer verdaderos ciudadanos, $y$ de este modo hacer Patria L... J, educar a la gente procurando el beneficio común e inculcándoles ideas de bonor y patriotismo, dando ejemplo de todo ésto ${ }^{43}$.

(39) Creemos que los contenidos ideológicos que llenan su lucha política no están sistemáticamente argumentados, sino que han sido adoptados de forma progresiva a lo largo de su vida. Con gran firmeza, eso si, como puede desprenderse de su acalorada defensa, pero sin una reflexión teórica, tal y como se trasluce por la exposición desordenada y la argumentación, en muchos casos, insuficiente. Este detalle fue compartido con el régimen político que lo encumbró: la Dictadura de Primo de Rivera. La ausencia de una verdadera teoría política es un defecto que, de manera generalizada, se le ha achacado a este régimen desde su mismo nacimiento, desde Ortega y Gasset hasta una gran mayoría de los investigadores actuales de este período histórico.

(40) Cfr. CARO CANCELA, D.: La Segunda Repüblica en... Op. Cü. pp. 132-134.

(41) CARRANZA, R. de: Discurso pronunciado por... Op. Cit. pp. 8-9.

(42) La Información, 9 de agosto de 1931; Cfr. CARO CANCELA, D.: La Segunda Répuiblica en... Op. Cit. pp. 127-128.

(43) CARRANZA, R. de: Discurso pronunciado por... Op. Cit. p. 8. Un cierto sentimiento de educadores de la clase obrera tuvieron los burgueses gaditanos, de forma manifiesta, ya desde principios de siglo. Afirmaciones tales como contribuir al refinamiento cultural de los operarios de la región gaditana o implicar en el proyecto regenerador gaditano a todos los sectores sociales, nos hablan de ello, PEREZ SERRANO, J. : -Gaditanismo y Andalucismo. Orígenes de la conciencia andaluza en el Cádiz de la Restauración borbónica. En: Actas del III Congreso sobre el Andalucismo Histórico. Granada, 1987, p. 412. 
- Trabajo: El tema de la clase obrera y de la ccuestión social. (un término que, desde principios de siglo, se había convertido en un tópico tal, que llegó a aparecer en libretos de varias Zarzuelas y piezas teatrales) se intentó presentar como uno de los de máxima preocupación, más empujado por las circunstancias políticas que por unos deseos explícitos. La envoltura del asunto tiene colores de paternalismo y unas ciertas connotaciones populistas. La clave estaría en una buena política de beneficencia, con la cual los problemas sociales quedarían resúeltos. Términos como "misión tutelar del Municipio", no sólo por deber sino por bumanidad, ,los que precisan protección y ayuda..., nos hablan de esta actitud paternalista, que queda aún más fortalecida al buscar inspiración en el Cristianismo, pues Cristo vino a la tierra para hacer iguales a todos los bombres ${ }^{44}$.

Carranza recuerda nuevamente su política anterior en tal sentido (el Asilo de la Infancia, la Casa de Maternidad, la Farmacia Municipal, el Casino para Obreros aque hoy se llama Casa del Pueblo y tiene otro objetivo muy diferente del que yo me propuse", las construcciones de "Casas Baratas"...) para mostrar su capacidad para llevar a buen término estos temas.

Hasta aquí nada es realmente sorprendente, lo insólito del caso es que Ramón de Carranza llega a sostener que el régimen político capaz de llevar a cabo una auténtica labor social es una Dictadura como la de Primo de Rivera. Las razones son, según él, sencillas: si el derecho de todos a ser iguales y a tener trabajo digno debe inspirarse en el Cristianismo, es difícil que un gobierno como el republicano plantee y regule estas teorías cristianas. Sólo una Dictadura podria implantarlas, y a ella todos nos someteriamos (...). Estos son los motivos principales que se me ofrecen para estimar conveniente la continuación todavia de este sistema de gobierno que yo pedia, fijaos bien, para establecer las leyes sociales que debian regular la vida de los que no tienen para vivir, además de dar tiempo a que el país y sus ciudadanos estén capacitados para disfrutar de todas las libertades que debemos tener los hombres del siglo $X X^{45}$. Y si la Dictadura es el régimen que ampararía la solución de los problemas laborales, el mecanismo utilizado sería también sencillo: "A unos les falta y a otros les sobra; pues una parte de esas sobras deben ir a aquellos que carecen de lo necesario (...). En plena Dictadura sinteticé mi criterio en este tan importante asunto de las clases obreras. No podrän pensar abora que lo bago para alagar a los obreros con motivo de las elecciones ${ }^{46}$.

Resulta llamativo el alejamiento de la realidad del momento que contenían estas ideas. Como Carranza detestaba la desorganización, pensó

(44) CARRANZA, R. de: Discurso pronunciado por... Op. Cit.. pp. 9-11.

(45) Ibidem. p. 13.

(46) Ibidem. p. 13. 
que la forma más conveniente de canalizar el reparto de riquezas de los que más tienen a los que menos, sería la de elevar los impuestos sobre herencias: por aquello de ajos que no ven, corazón que no siente, si en la vida de cada uno no se le ha quitado nada, menos habrá de sentirse que la merma de bienes sea para los herederos en vez de para uno mismo.47.

Es curiosa la defensa de esta solución por parte de un personaje perteneciente a la burguesía que, en parte, a través de un capital heredado, construyó su fortuna personal.

El convencimiento de que rcuando estaban en el Ayuntamiento los que sólo atendian al mejoramiento moral y material del pueblo", los problemas sociales estaban en mejor situación que con el régimen republicano, era fortalecido con una serie de indicaciones acerca de la mala situación económica de los Astilleros de Echevarrieta: el Ayuntamiento y los diputados republicanos no habían obtenido ninguna concesión de trabajo, mada absolutamente [...] Ahora se ba concedido a la Constructora la reparación del crucero República l... y se arma alharaca con tal concesión. Compärese con la construcción de los cuatro petroleros de ocho mil toneladas y doce millones de pesetas cada uno que nos concedió el anterior régimen l... J gracias a nuestras constantes gestiones, sin dietas ni viajes ${ }^{48}$.

Una vez más, desacreditado el gobierno de la República, se conduce al auditorio a concluir que el camino correcto era el ofrecido por Carranza. Sin embargo, tanto afán por solucionar los problemas laborales encuentra una contradicción en el tratamiento del subsidio a los obreros parados del que no era partidario pues es difícil distinguir cuáles son los temporalmente parados por falta de trabajo, cuáles por falta de voluntad para trabajar, $y$, aparte de ésto, porque [...entendía] que todos los que perciben estos subsidios pierden los hábitos de trabajo, y la principal riqueza de una nación estriba en que sus habitantes sean muy trabajadores ${ }^{49}$.

Desconfiando, en cada caso, de la verdadera necesidad o no de trabajo, colocó en entredicho su voluntad por encontrar los caminos de solución de los problemas de la *cuestión social.

- La mujer. Una especial circunstancia motiva que la postura de Ramón de Car:anza en este tema no sea la que, a simple vista y conociendo su trayectoria política, podría esperarse. La causa era bien simple: existía, entre los grupos políticos de la derecha, la conciencia clara de la importancia que el voto de la mujer podía tener en sus resultados electorales. Era un voto, pues, que había que mimar y que asegurar.' Esto motivaría que hablase de la mujer como un ser humano cual bombre,

(47) Ibidem, pp. 13-14.

(48) Ibidem, pp. 23-24.

(49) La Información, 2 de mayo de 1933. 
todo lo dicho para él, debe serle aplicable y tener igualmente derecho al sustento por su trabajo como el hombre, y no lo que basta abora ha venido ocurriendo [...J Muchas no tienen otra carrera que la de servir por un salario o la de casarse con el primero que se les presente para servirle de mujer y de criada, o tomar otro oficio peor. No puede ésto, ni debe, continuar más tiempo l...l ¿Y la mujer? ¿no es igual al bombre? ¿es acaso un animal, un fenómeno? [... Los jornales que ganan las mujeres cuando trabajan son irrisorios y deben estar en proporción del servicio que bagan, no mirando al sexo que pertenecen), 50 .

Era evidente el deseo de Carranza de ganarse la voluntad de la mujer, y más en concreto, de la mujer obrera, al defender unas posiciones abiertamente en favor de sus derechos. "La mujer siempre ba demostrado más espíritu, mäs perspicacia que los bombres $y$, muchas veces, también más valor. Con las elecciones en que iba a decidirse el inmediato porvenir de la Patria, que iría a la ruina si venia el socialismo, pobres y ricas, jóvenes y ancianas, solteras y casadas, todas a una, decidieron, casi sin consultarse, votar por las candidaturas de derechas [...] En verdad que el éxito de la elección a ellas se debe, pues los bombres faltaron a su deber de ciudadanos en emitir su voto l...J Estas elecciones pasarán a la posteridad con el nombre de la Elección de la Mujeres. ${ }^{51}$.

- Religión y Familia: Buscando, como indicábamos, la inspiración en la doctrina cristiana para la perfecta solución de la "cuestión social, y siendo uno de sus puntos de ataque contra la República su carácter irreligioso, no quedan dudas acerca del peso que tuvieron los sentimientos religiosos dentro del cuadro ideológico de Ramón de Carranza y de sus seguidores. Unido a ello, la familia como cimiento básico para el sostenimiento de la sociedad. Para Carranza, los ciudadanos tienen derechos que son respetables pero tienen deberes que cumplir. El primer deber de ciudadanos es el deber con el Supremo Hacedor que nos creó; el segundo deber es atender a la familia que El ba creado. Después de eso, es el deber a su profesión [...] El cuarto deber que tiene es el ocuparse del municipio de la ciudad en que está (...J un deber para con la Patria $\omega^{52}$. Las prioridades dadas por Carranza a los deberes ciudadanos son lo suficientemente explicativas de este punto de su pensamiento.

- Orden: Un fuerte rechazo a todo lo que pueda parecerse a revuelta, anarquismo o desorganización van salpicando las manifestaciones públicas de Ramón de Carranza. En ellas, el ‘orden» era señałado como

(50) CARRANZA, R. de: Discurso pronunciado por... Op. Cit. p. 12.

(51) La Información, 22 de noviembre de 1933; Cfr. CARO CANCELA, D.: La Segunda Repuiblica en... Op. Cut. pp. 197-198.

(52) CARRANZA, R. de: Discurso pronunciado por... Op. Cit. pp. 24-25. 
uno de los principales valores a defender. Su idea era que se podía - disfrutar de todas las libertades que debemos tener los bombres del siglo $X X$, no confundiéndolas en modo alguno con el libertinaje y el derecho a molestar y a atropellar a todos los que no piensen como ellos quisieran [...] De no resolverlo es fácil sobrevenga el caos ${ }^{53}$.

- Política y Administración: Conectado con la dialéctica regeneracionista de Miguel Primo de Rivera, a la que se habían sumado muchos de los caciques que debían haber sido neutralizados políticamente por pura supervivencia, Carranza manifiesta abiertamente su aversión por "la Política", un "monstruo causante de todas las desdichas." Esta fue quizás la única línea ideológica firme e invariable dentro del poco coherente y sólido programa político de Miguel Primo de Rivera. Ramón de Carranza, como heredero de este pensamiento, muestra este rechazo por la práctica política pura de manera contundente. Llega a afirmar que si aqui existiera verdadero patriotismo y el amor a la patria se antepusiese al interés partidista todo iría mejor. En definitiva, lo que hacía falta era menos politica y a trabajar por la ciudad. Es preciso que decidais si Cádiz debe o no morir l...J Sólo el cariño e interés por Cádiz voy a tratar, y nada de política, pues considero es más importante para los obreros la provisión de elementos para su bienestar económico y material que la resolución de cualquier problema politico puro.55.

Así pues, en opinión de Carranza, el cariño por Cádiz y la Patria eran incompatibles con la política, que no se ocupaba del bienestar económico de los obreros. Era, por consiguiente, nefasta para la sociedad. Pero aún hay más: los que no administraban ni trabajaban y sólamente se dedicaban a la política fueron los Ayuntamientos republicanos. Trabajar y hacer política eran para don Ramón conceptos irreconciliables y fue, precisamente, la República la que consagraría este mal nacional. Una razón más para llegar a la conclusión general que se pretendía generar entre el vecindario: la única vía de salvación para los problemas existentes en la ciudad tenían un nombre: Ramón de Carranza. Su mensaje al pueblo de Cádiz fue preciso: "Quiero saber si el día que os necesite para trabajar por Cádiz y por España, podré contar con vosotros [... ¿ ¿ Podré contar con vosotros, con todos como un sólo hombre y un sólo corazón que lata al par que el mio?, respondedme, si o no. Estamos conformes, ¿si o no? 35 .

(53) Ibidem. p. 13.

(54) Vid. PABON, J.: Cambó. tomo Il. Barcelona, 1969. p. 466; TUSELL, J.: La crisis del caciquismo... Op. Cit. pp. 118-119

(55) La Información, 2 de mayo de 1933.

(56) CARRANZA, R. de: Discurso pronunciado por... Op. Cit. p. 25. 
En aquella ocasión el público presente gritó jsi!, pero el momento de ver cumplidas las esperanzas de reanudar su labor política no tendrían efecto hasta julio de 1936, cuando Carranza fue nombrado por el general Queipo de Llano Alcalde y Gobernador Civil de Cádiz. Sólo su muerte, catorce meses después, pudo impedirle ver satisfechas sus pretensiones ${ }^{7}$.

(57) Cfr. Diario de Cádiz, 20 de julio de 1936. 